\title{
Editorial
}

\section{Insulin Resistance, Type 1 and Type 2 Diabetes, and Related Complications 2015}

\author{
Joseph Fomusi Ndisang, ${ }^{1}$ Sharad Rastogi, ${ }^{2}$ and Alfredo Vannacci ${ }^{3}$ \\ ${ }^{1}$ Department of Physiology, University of Saskatchewan College of Medicine, 107 Wiggins Road, Saskatoon, SK, Canada S7N 5E5 \\ ${ }^{2}$ The Medical Affairs Company, Cardiovascular Division, 43229 Dequindre Road, Troy, MI 48085, USA \\ ${ }^{3}$ Department of Neurosciences, Psychology, Drug Research and Child Health, Section of Pharmacology and Toxicology, \\ University of Florence, Viale Pieraccini 6, 50139 Florence, Italy
}

Correspondence should be addressed to Joseph Fomusi Ndisang; joseph.ndisang@usask.ca

Received 9 June 2015; Accepted 9 June 2015

Copyright (C) 2015 Joseph Fomusi Ndisang et al. This is an open access article distributed under the Creative Commons Attribution License, which permits unrestricted use, distribution, and reproduction in any medium, provided the original work is properly cited.

The dramatic increase in obesity and diabetes worldwide poses a huge socioeconomic burden to healthcare systems. In type 1 diabetes, autoimmune-mediated destruction of pancreatic beta-cell results in insulin deficiency [1]. Obesity is one of the major causes of type 2 diabetes [1-3]. In type 2 diabetes, a combination of peripheral insulin resistance and aberrant production of insulin are amongst the paradox commonly encountered in the pathogenesis of the disease [1$3]$. However, both forms of diabetes are characterized by elevated inflammation/oxidative stress, glucotoxicity, lipotoxicity, endoplasmic reticulum-induced stress with increased apoptosis and necrosis that ultimately leads to destruction loss of beta cells, and related complications including cardiomyopathy, nephropathy, neuropathy, and hepatopathy $[1,4-7]$. Although insulin resistance has traditionally been associated with type 2 diabetes, recent evidence suggests that insulin resistance in type 1 diabetes is increasing [8-10]; therefore, novel mechanistic approaches deciphering insulin resistance are needed.

The etiology of insulin resistance is complicated and several factors are implicated, so deciphering this multifaceted disease remains challenging, although a wide body of evidence suggests that oxidative stress, inflammation, genetic, habitual, environmental, and epigenetic factors may be involved $[1,11]$. Thus, further research is needed for more indepth and comprehensive understanding of the pathophysiology of insulin resistance in both type 1 and type 2 diabetes, and especially in situations where diabetes is comorbid with other chronic conditions such as obesity and hypertension.
This special issue will showcase a broad spectrum research and review papers addressing thematic problems associated with insulin resistance, type 1 diabetes, type 2 diabetes, and related complications. To underscore the role of insulin resistance in children, M. P. van der Aa et al. wrote a research article on the prevalence and incidence of childhood insulin resistance, while S.-H. Nam and coworkers investigated the effects of cardioankle vascular index on metabolic syndrome, a multifactorial condition characterized by insulin resistance, dyslipidemia, hyperglycemia, hypertension, and other factors. Similarly, R. Burrows et al. gave further insights for diagnosing metabolic syndrome in adolescents in a research article. In another related research article, M. Fabregat et al. investigated the genetic profile of human leukocyte antigen (HLA) alleles and non-HLA in type 2 diabetes, while P. Tiwari wrote a systematic review about the current therapeutic strategies for the management of diabetes. Given that diabetes and hypertension are characterized by elevated inflammation/oxidative stress $[4,12-14]$ and these two pathophysiological driving forces are implicated in many cardiac complications [4, 12-14], J. Klen et al. investigated the role of NLRP3 inflammasome polymorphism in type 2 diabetes, shedding novel insights on the role of NLRP3 polymorphism on myocardial infarction, a macrovascular complication of diabetes. Similarly, H. Al-Safar et al. investigated the role of genetic polymorphisms on transcription-factor-7-like 2 and peroxisome proliferator-activated receptors- $\gamma 2$ in type 2 diabetes and obesity, while M. Guclu et al. wrote a research 
article about the effects of combination therapy with rosiglitazone and insulin on inflammatory insults in patients with type 1 diabetes. In another related research article, $\mathrm{Z}$. Yida et al. reported that cotreatment with the cholesterol lowering drug simvastatin and edible bird's nest (EBN), a traditional product commonly consumed in Asia for its nutritional value, improved insulin signaling in a rat model of highfat diet-induced insulin resistance. Consistently, in another related study, A. Ferreira-Hermosillo et al. gave further insights on the role of inflammatory cytokines in patients with metabolic syndrome. Within the same theme of insulin resistance and metabolic syndrome, R. Adela and S. K. Banerjee wrote a review article to underscore the role of growthdifferentiation-factor-15 in diabetes and related cardiovascular diseases, whereas J. Zhang et al. gave further insights on obesity and type 2 diabetes in a research article. By the same token, T.-Y. Chuang et al. reported the effects of microRNA223 on insulin resistance by studying the adipose tissue. Finally, S. Riaz wrote an article giving novel insights on the role of Vitamin B1 on biomarkers of diabetes type 2 diabetes.

Collectively, the articles featured in this special issue cover a wide spectrum of thematic issues of great interest and would benefit a wide audience.

\section{Joseph Fomusi Ndisang Sharad Rastogi Alfredo Vannacci}

diabetes' and what are the risks?" Diabetologia, vol. 56, no. 7, pp. 1462-1470, 2013.

[9] N. J. Nokoff, M. Rewers, and M. C. Green, "The interplay of autoimmunity and insulin resistance in type 1 diabetes," Discovery Medicine, vol. 13, no. 69, pp. 115-122, 2012.

[10] J. F. Ndisang and A. Jadhav, "Heme oxygenase system enhances insulin sensitivity and glucose metabolism in streptozotocininduced diabetes," The American Journal of Physiology-Endocrinology and Metabolism, vol. 296, no. 4, pp. E829-E841, 2009.

[11] H. Slomko, H. J. Heo, and F. H. Einstein, "Minireview: epigenetics of obesity and diabetes in humans," Endocrinology, vol. 153, no. 3, pp. 1025-1030, 2012.

[12] A. Jadhav and J. F. Ndisang, "Heme arginate suppresses cardiac lesions and hypertrophy in deoxycorticosterone acetate-salt hypertension," Experimental Biology and Medicine, vol. 234, no. 7, pp. 764-778, 2009.

[13] J. F. Ndisang and R. Wang, "Age-related alterations in soluble guanylyl cyclase and cGMP pathway in spontaneously hypertensive rats," Journal of Hypertension, vol. 21, no. 6, pp. 1117-1124, 2003.

[14] J. F. Ndisang, R. Wang, A. Vannacci et al., "Haeme oxygenase-1 and cardiac anaphylaxis," British Journal of Pharmacology, vol. 134, no. 8, pp. 1689-1696, 2001.

\section{References}

[1] P. Wang, N. M. Fiaschi-Taesch, R. C. Vasavada, D. K. Scott, A. García-Ocaña, and A. F. Stewart, "Diabetes mellitusadvances and challenges in human beta-cell proliferation," Nature Reviews Endocrinology, vol. 11, pp. 201-212, 2015.

[2] P. Hossain, B. Kawar, and M. El Nahas, "Obesity and diabetes in the developing world-a growing challenge," The New England Journal of Medicine, vol. 356, no. 3, pp. 213-215, 2007.

[3] WHO, "Obesity and overweight," Fact Sheet No. 311, World Health Organization, Geneva, Switzerland, 2006.

[4] A. Jadhav, S. Tiwari, P. Lee, and J. F. Ndisang, "The heme oxygenase system selectively enhances the anti-inflammatory macrophage- $\mathrm{m} 2$ phenotype, reduces pericardial adiposity, and ameliorated cardiac injury in diabetic cardiomyopathy in zucker diabetic fatty rats," Journal of Pharmacology and Experimental Therapeutics, vol. 345, no. 2, pp. 239-249, 2013.

[5] T. N. Salley, M. Mishra, S. Tiwari, A. Jadhav, and J. F. Ndisang, "The heme oxygenase system rescues hepatic deterioration in the condition of obesity co-morbid with type-2 diabetes," PLoS ONE, vol. 8, no. 11, Article ID e79270, 2013.

[6] T. Chen, D. Song, G. Shan et al., "The association between diabetes mellitus and nonarteritic anterior ischemic optic neuropathy: a systematic review and meta-analysis," PLoS ONE, vol. 8, no. 9, Article ID e76653, 2013.

[7] F. Murata, I. Horie, T. Ando et al., "A case of glycogenic hepatopathy developed in a patient with new-onset fulminant type 1 diabetes: the role of image modalities in diagnosing hepatic glycogen deposition including gradient-dual-echo MRI," Endocrine Journal, vol. 59, no. 8, pp. 669-676, 2012.

[8] S. J. Cleland, B. M. Fisher, H. M. Colhoun, N. Sattar, and J. R. Petrie, "Insulin resistance in type 1 diabetes: what is 'double 


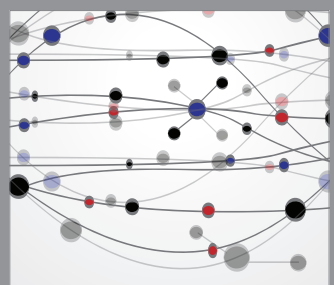

The Scientific World Journal
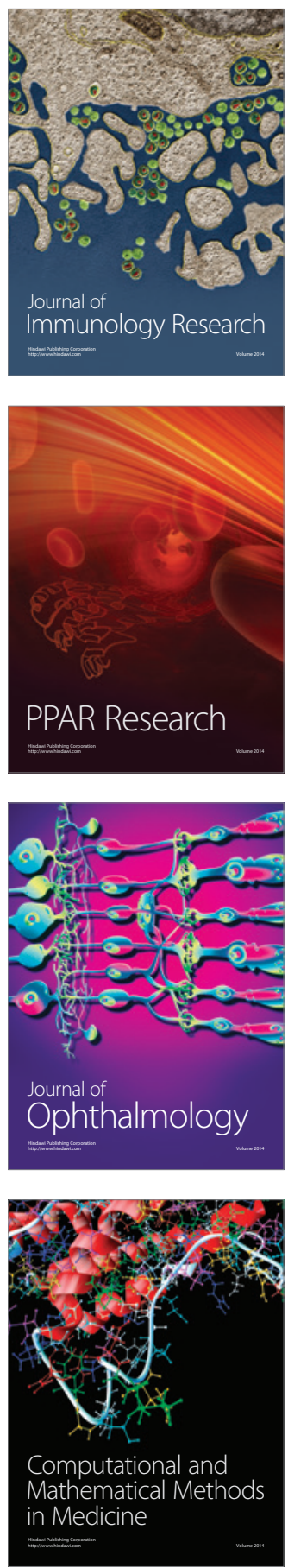

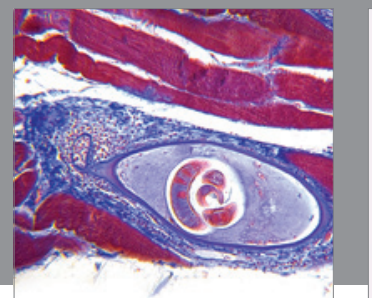

Gastroenterology

Research and Practice
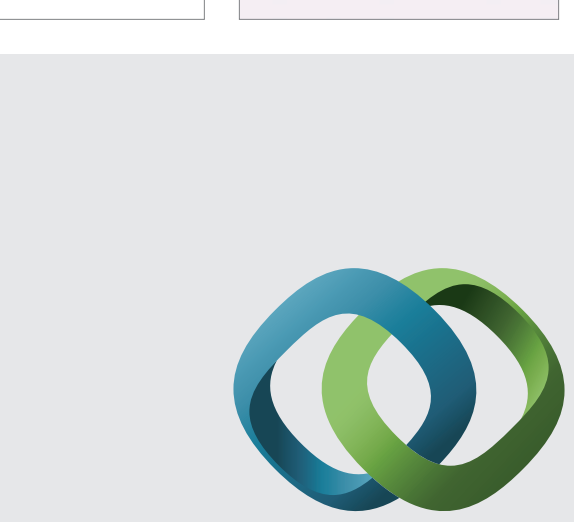

\section{Hindawi}

Submit your manuscripts at

http://www.hindawi.com
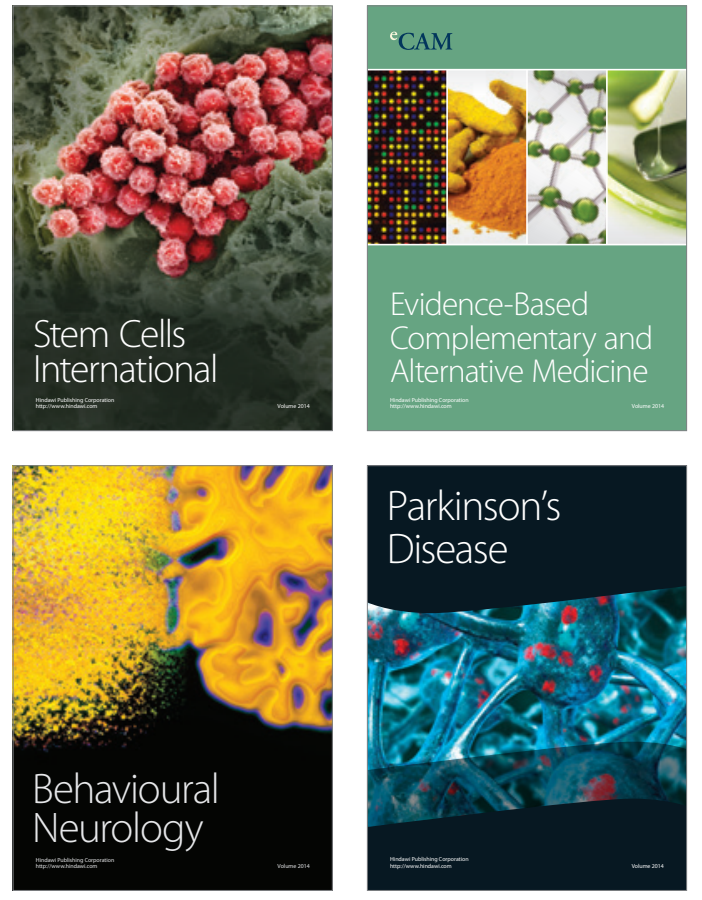
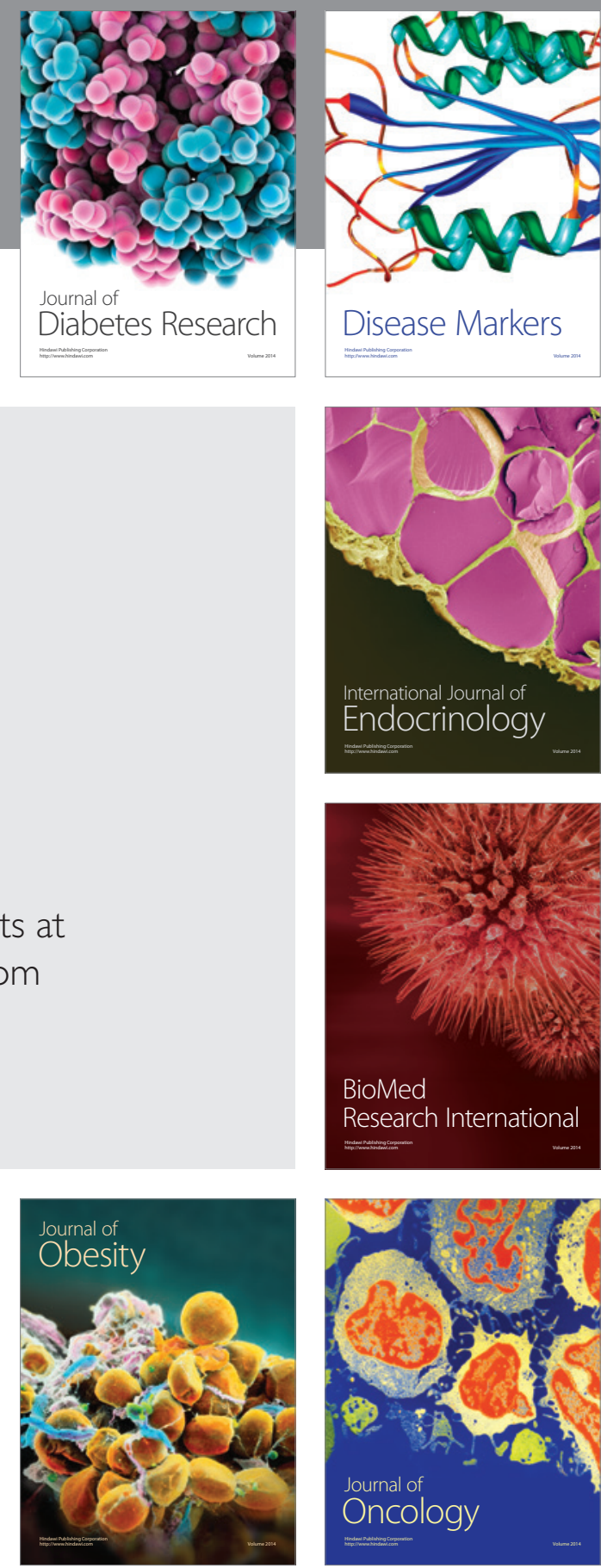

Disease Markers
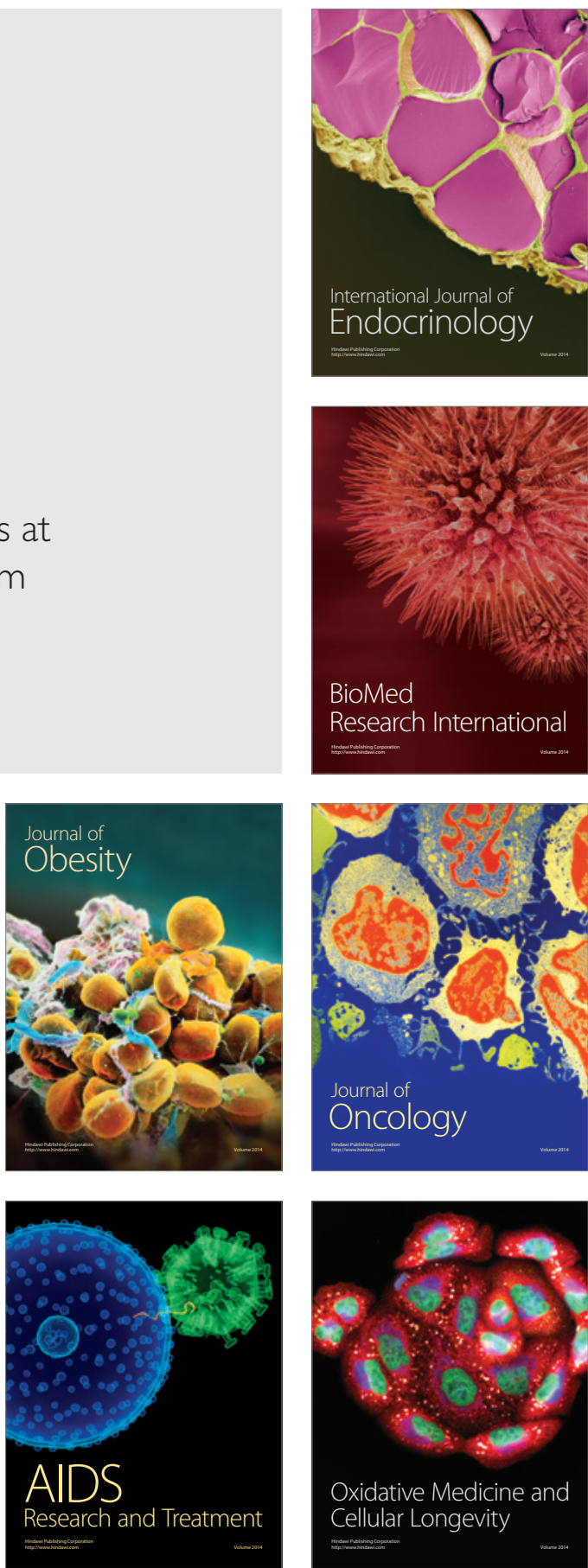